\title{
An Appraisal of Demographic Parameters of Goat Farmers of Punjab
}

\author{
Sukhwinder Singh ${ }^{1}$, Rajesh Kasrija ${ }^{1 *}$, Parminder Singh ${ }^{1}$, \\ Jaswinder Singh ${ }^{1}$ and Mandeep Singla ${ }^{2}$ \\ ${ }^{1}$ Department of Veterinary and Animal Husbandry Extension Education, \\ ${ }^{2}$ Department of Livestock Production and Management, Guru Angad Dev Veterinary and \\ Animal Sciences University, Ludhiana, India \\ *Corresponding author
}

\section{A B S T R A C T}

Keywords

Demography,

Farmer, Goat, Parameters, Punjab

Article Info

Accepted:

15 December 2019 Available Online: 20 January 2020
The present study was conducted in all the six different agro-climatic zones of Punjab state to know about demographic profile parameters (age, sex, education, main occupation, family size, family type, land holdings and category) of farmers engaged in goat farming. A total of 240 goat farmers ( 40 from each agro-climatic zone) were randomly selected. The farmers were interviews personally at their farm with the help of structured interview schedule. The statistical analysis of data revealed that in Punjab most of the goat farmers $(62.50 \%)$ were between age group 31-60 years. Very few $(0.83 \%)$ goat farmers were female. The education level of most of the goat farmers was not up to mark being $52.08 \%$ illiterate. The main occupation of majority $(78.32 \%)$ of farmers engaged in rearing goats is goat farming. $50 \%$ farmers had medium size and joint families. Majority (74.58\%) of goat farmers were landless. $47.50 \%$ goat farmers belonged to schedule caste, followed by $33.75 \%$ belonging to general caste, $11.25 \%$ belonging to backward class and $7.5 \%$ belonging to other backward classes. Age, education, main occupation, family size, family type and land holding were significantly correlated. The present study gives an insight into the demographic parameters of goat farmers of Punjab for organizing effective extension activities for goat farmers.

\section{Introduction}

Goats provide their owners with a broad range of products and socio-economic services and have played an important role in the social life of many people being used as gifts, dowry, in religious rituals and rites of passage (Peacock 1996). Also, goat rearing plays a vital role in food and economic security of rural people, especially landless, marginal and small farmers (Chander and Rathod, 2015). Goats act as a ready to use economic asset at time of crisis among rural farmers (Lebbie, 2004) by providing meat, milk, hide, manure and wool. Goats can quickly multiply and are easily convertible to cash to meet financial needs of the rural producers. So, they are also known as moving ATM. Also, the rural poor who cannot afford to maintain a cow or a buffalo find goat as the best alternative source of supplementary 
income and milk. So, Goats are also known as Poor man's cow. However, poor productivity and lack of scientific knowledge about goat farming proves to be the lacunae behind goat production in rural India (Mohan et al., 2009). The extension machinery provides an ideal bridge between research institutions and farmers for their catalytic effects (Meena and Malik 2009). For knowledge enrichment to the goat farmer, various training programmes and extension activities are carried out. But for effective implementation of an extension activity, awareness about demographic parameters (age, sex, education, main occupation, family size, family type, land holdings and category etc.) of goat farmers is must, which help in planning and implementing of activity. So, a comprehensive study about demographic parameters of goat farmers is planned.

\section{Materials and Methods}

The present study was conducted in whole of Punjab state. On the basis of agro-climatic conditions, Punjab state has been divided into six different agro-climatic zones (Mahi and Kingra, 2013). These include: sub mountain undulating zone (zone I), undulating plain zone (zone II), central plain zone (zone III), western plain zone (zone IV), western zone (zone V) and flood plain zone (zone VI). From each agro-climatic zone, 40 goat farmers were randomly selected. Thus, the total number of respondents was 240 from all the six agroclimatic zones.

The goat farmers were personally interviewed with the help of pre-structured and pre-tested interview schedule by visiting their farm at field level. To avoid the influence of other farmer's opinions, the goat farmers were interviewed separately. The data was recorded after noting expressed opinion and after observing the things physically at goat farm. Age is the period of time someone has been alive and refers to the chronological age of the goat farmer in years. On basis of age, the goat farmers has been categorized into: $\leq 30$ years (young), 31-60 years (middle) and $>60$ years (Old). Education refers to the academic qualification of goat farmer acquired through formal school and college education at the time of interview for data collection. Goat farmers had been categorized on basis of years of schooling in to- Illiterate (No formal education), up to Middle (1-8), high school (10), higher secondary and above $(\geq 11)$ and graduation and post-graduation (>12). On the basis of main occupation, goat farmers has been categorized into - Agriculture, Goat farming, Labour/Service/Business. On basis of family size, goat farmers were classified into small (members up to 4), medium (members 5 - 8) and large (members more than 8) by following the same procedure as by Kasrija (2016).

For land holding, the goat farmers were categorized after as done by Kasrija (2016) in to Landless (without land), Small ( $<5$ acres), Medium (5 - 10 acres) and Large (> 10 acres). Also, the goat farmers were categorized in to General category, Schedule caste, Backward class and other Backward classes. The data was tabulated and put to suitable statistical analysis with the help of SPSS version 20.0.

\section{Results and Discussion}

It is clear from Table 1 that most of the goat farmers from agro-climatic zone I, II, IV, V, VI and Overall Punjab were in age group between 31-60 years, while in Zone III most of the farmers were less than 30 years. Figure 1 depicts age of goat farmers in Punjab. Tanwar et al., 2008 also reported that in the tribal area of Udaipur district of Rajasthan, majority of the goat farmers belonged to 31-50 years of age group. Also in Nathdwara, Vallabhnagar, Railmagra and Devgarh areas of Rajasthan the majority of goat rearers were 
reported to be belonging to middle age group (Sharma et al., 2007).

It is clear from Table 1 that Majority of goat farmers in all the six zones and in overall Punjab were male. Very less number of Women farmers $(0.83 \%)$ were practicing goat farming Figure 2) in Punjab. However, Neupane et al., 2018 reported that in Nepal, goat is the most popular small ruminant which can be handled by women and children in absence of young male members. This indicated that goat farming was practiced mainly by mature male farmers and their age and sex should be taken in to consideration while planning any extension activity related to goat farming. Also, there is dire need to encourage women farmers to actively participate in goat rearing practices, as goat farming can play an important role in women empowerment.

Majority of the goat farmers in present study were illiterate and very few were graduate or above in all the six zones and in overall Punjab (Table 1 and Figure 3). So, the education level of goat farmers should also be kept in mind while formulating any extension strategies for them. The knowledge enrichment programme for goat farmers should be devised in local and easily understandable language. The main occupation of respondents under study was reported to be goat farming, followed by agriculture then labour/service (Table 1 and Figure 4). This suggest that large number of farmers involved in rearing of goats were surviving mainly on goat farming, thereby making goat farming as main source of livelihood.

Most of the goat farmers of Zone II, III, VI and overall Punjab had medium size families (Table 1 and Figure 5). This indicate that for a number of family members the main source of livelihood is goat farming. Arya and Chander 2000 also reported that the families which had more number of children were more inclined to keep goats as the children could be used for taking goats to grazing on fallow land, harvested fields, alongside roads and other uncultivated areas. Most of the farmers in all the six zones and in overall Punjab were landless (Table 1 and Figure 6). Similar findings were reported by Tanwar et al., 2008 in Udaipur district of Rajasthan where majority of goat farmers were illiterate and had medium size family and small land holding. Lalwar et al., 2009 also reported that in Maharastra, Sangamneri goats were reared by majority of landless labourers.

The goat farming in overall Punjab were practiced mostly by Schedule caste, followed by General caste, then backward class and other backward classes (Table 1 and Figure 7).

Singh et al., 2013 reported that majority of goat-keepers in Bundelkhand region of Uttar Pradesh belonged to the backward social community (54\%), followed by schedule caste $(37 \%)$ and general category $(9 \%)$. Goat was kept by all categories of farmers though its contribution to income was more among marginal and small farmers in both the districts. Sharma et al., 2007 reported that in Nathdwara, Vallabhnagar, Railmagra and Devgarh areas of Rajasthan, majority of goat rearers belonged to middle age group and other backward caste category.

A perusal of Table 2 indicate that age, education, main occupation, family size, family type and land holding are significantly correlated. This indicate that more the age of goat farmer, more will be his education level, main occupation as goat farming, large family size, joint family and more land holding. 
Table.1 Distribution of goat farmers according to demographic profile in different agro-climatic zones of Punjab

\begin{tabular}{|c|c|c|c|c|c|c|c|c|}
\hline Attributes & Parameter & $\begin{array}{l}\text { Zone I } \\
(\mathrm{n}=40)\end{array}$ & $\begin{array}{l}\text { Zone II } \\
(\mathrm{n}=40)\end{array}$ & $\begin{array}{l}\text { Zone III } \\
(\mathrm{n}=40)\end{array}$ & $\begin{array}{l}\text { Zone IV } \\
(\mathrm{n}=40)\end{array}$ & $\begin{array}{l}\text { Zone V } \\
(\mathrm{n}=40)\end{array}$ & $\begin{array}{c}\text { Zone VI } \\
(\mathrm{n}=40)\end{array}$ & $\begin{array}{l}\text { Overall } \\
(\mathbf{n}=\mathbf{2 4 0})\end{array}$ \\
\hline \multirow[t]{3}{*}{ Age (years) } & $\leq 30$ years & $4(10.00)$ & $10(25.00)$ & $22(55.00)$ & $5(12.50)$ & $16(40.00)$ & $6(15.00)$ & $63(26.25)$ \\
\hline & $31-60$ & $30(75.00)$ & $24(60.00)$ & $17(42.50)$ & $31(77.50)$ & $21(52.50)$ & $27(67.50)$ & $150(62.50)$ \\
\hline & $>60$ & $6(15.00)$ & $6(15.00)$ & $1(2.50)$ & $4(10.00)$ & $3(7.50)$ & $7(17.50)$ & $27(11.25)$ \\
\hline \multirow{2}{*}{ Sex } & Male & $39(97.50)$ & $39(97.50)$ & $40(100)$ & $40(100)$ & $40(100)$ & $40(100)$ & $238(99.16)$ \\
\hline & Female & $1(2.50)$ & $1(2.50)$ & $0(0.00)$ & $0(0.00)$ & $0(0.00)$ & $0(0.00)$ & $2(0.83)$ \\
\hline \multirow[t]{5}{*}{ Education } & Illiterate & $25(62.50)$ & $14(35.00)$ & $17(42.50)$ & $28(70.00)$ & $18(45.00)$ & $23(57.50)$ & $125(52.08)$ \\
\hline & Up to middle & $11(27.50)$ & $10(25.00)$ & $6(15.00)$ & $5(12.50)$ & $5(12.50)$ & $8(20.00)$ & $45(18.75)$ \\
\hline & High School & $2(5.00)$ & $10(25.00)$ & $7(17.50)$ & $5(12.50)$ & $8(20.00)$ & $5(12.50)$ & $37(15.41)$ \\
\hline & Higher secondary & $2(5.00)$ & $6(15.00)$ & $9(22.50)$ & $1(2.50)$ & $6(15.00)$ & $4(10.00)$ & $28(11.66)$ \\
\hline & Graduate and Postgraduate & $0(0.00)$ & $0(0.00)$ & $1(2.50)$ & $1(2.50)$ & $3(7.50)$ & $0(0.00)$ & $5(2.08)$ \\
\hline \multirow[t]{3}{*}{ Main occupation } & Agriculture & $6(15.00)$ & $6(15.00)$ & $8(20.00)$ & $7(17.50)$ & $14(35.00)$ & $5(12.50)$ & $46(19.61)$ \\
\hline & Goat farming & $33(82.50)$ & $30(75.00)$ & $32(80.00)$ & $33(82.50)$ & $26(65.00)$ & $34(85.00)$ & $188(78.32)$ \\
\hline & Labour/Service/ Business & $1(2.50)$ & $4(10.00)$ & $0(0.00)$ & $0(0.00)$ & $0(0.00)$ & $1(2.50)$ & $6(2.50)$ \\
\hline \multirow[t]{3}{*}{ Family size } & Small $(\leq 4)$ & $17(42.50)$ & $16(40.00)$ & $12(30.00)$ & $18(45.00)$ & $18(45.00)$ & $12(30.00)$ & $93(38.75)$ \\
\hline & Medium ( 5-8) & $14(35.00)$ & $21(52.50)$ & $23(57.50)$ & $18(45.00)$ & $18(45.00)$ & $26(65.00)$ & $120(50.00)$ \\
\hline & Large ( >8) & $9(22.50)$ & $3(7.50)$ & $5(12.50)$ & $4(10.00)$ & $4(10.00)$ & $2(5.00)$ & $27(11.25)$ \\
\hline \multirow[t]{2}{*}{ Family type } & Single & $20(50.00)$ & $22(55.00)$ & $16(40.00)$ & $25(62.50)$ & $20(50.00)$ & $15(37.50)$ & $118(49.16)$ \\
\hline & Joint & $20(50.00)$ & $18(45.00)$ & $24(60.00)$ & $15(37.50)$ & $20(50.00)$ & $25(62.50)$ & $122(50.83)$ \\
\hline \multirow{4}{*}{$\begin{array}{l}\text { Land holdings } \\
\text { (Acres) }\end{array}$} & Landless & $33(82.50)$ & $33(82.50)$ & $26(65.00)$ & $31(77.50)$ & $21(52.50)$ & $35(87.50)$ & $179(74.58)$ \\
\hline & $(<5)$ & $4(10.00)$ & $6(15.00)$ & $10(25.00)$ & $8(20.00)$ & $8(20.00)$ & $2(5.00)$ & $38(15.83)$ \\
\hline & $5-10$ & $1(2.50)$ & $0(0.00)$ & $1(2.50)$ & $1(2.50)$ & $5(12.50)$ & $2(5.00)$ & $10(4.15)$ \\
\hline & $>10$ & $2(5.00)$ & $1(2.50)$ & $3(7.50)$ & $0(0.00)$ & $6(15.00)$ & $1(2.50)$ & $13(5.41)$ \\
\hline \multirow[t]{4}{*}{ Category } & General & $13(32.50)$ & $8(20.00)$ & $11(27.50)$ & $16(40.00)$ & $23(57.50)$ & $10(25.00)$ & $81(33.75)$ \\
\hline & Schedule caste & $25(62.50)$ & $16(40.00)$ & $18(45.00)$ & $15(37.50)$ & $15(37.50)$ & $25(62.50)$ & $114(47.50)$ \\
\hline & Backward class & $2(5.00)$ & $16(40.00)$ & $1(2.50)$ & $4(10.00)$ & $1(2.50)$ & $3(7.50)$ & $27(11.25)$ \\
\hline & Other backward class & $0(0.00)$ & $0(0.00)$ & $10(25.00)$ & $5(12.50)$ & $1(2.50)$ & $2(5.00)$ & $18(7.50)$ \\
\hline
\end{tabular}

Figure in parenthesis indicate percentage 
Table.2 Correlation analysis of different demographic parameters of goat farmers $(n=240)$ of Punjab

\begin{tabular}{|c|c|c|c|c|c|c|}
\hline $\begin{array}{c}\text { Pearson } \\
\text { Correlation } \\
\text { Sig. (2-tailed) }\end{array}$ & Age & Education & $\begin{array}{c}\text { Main } \\
\text { Occupation }\end{array}$ & $\begin{array}{c}\text { Family } \\
\text { size }\end{array}$ & $\begin{array}{c}\text { Family } \\
\text { type }\end{array}$ & $\begin{array}{c}\text { Land } \\
\text { holding }\end{array}$ \\
\hline Age & 1 & $0.599^{* *}$ & $0.220^{* *}$ & $0.642^{* *}$ & $0.599^{* *}$ & $0.479^{* *}$ \\
\hline Education & $0.599^{* *}$ & 1 & $0.206^{* *}$ & $0.652^{* *}$ & $0.642^{* *}$ & $0.705^{* *}$ \\
\hline $\begin{array}{c}\text { Main } \\
\text { Occupation }\end{array}$ & $0.220^{* *}$ & $0.206^{* *}$ & 1 & $0.217^{* *}$ & $0.220^{* *}$ & $0.153^{*}$ \\
\hline Family size & $0.642^{* *}$ & $0.652^{* *}$ & $0.217^{* *}$ & 1 & $0.711^{* *}$ & $0.589^{* *}$ \\
\hline Family type & $0.599^{* *}$ & $0.642^{* *}$ & $0.220^{* *}$ & $0.711^{* *}$ & 1 & $0.462^{* *}$ \\
\hline Landholding & $0.479^{* *}$ & $0.705^{* *}$ & $0.153^{*}$ & $0.589^{* *}$ & $0.462^{* *}$ & 1 \\
\hline
\end{tabular}

(**) - Correlation is significant at the 0.01 level (2-tailed)

(*) - Correlation is significant at the 0.05 level (2-tailed)

Fig.1 Age of goat farmers $(n=240)$ in overall Punjab

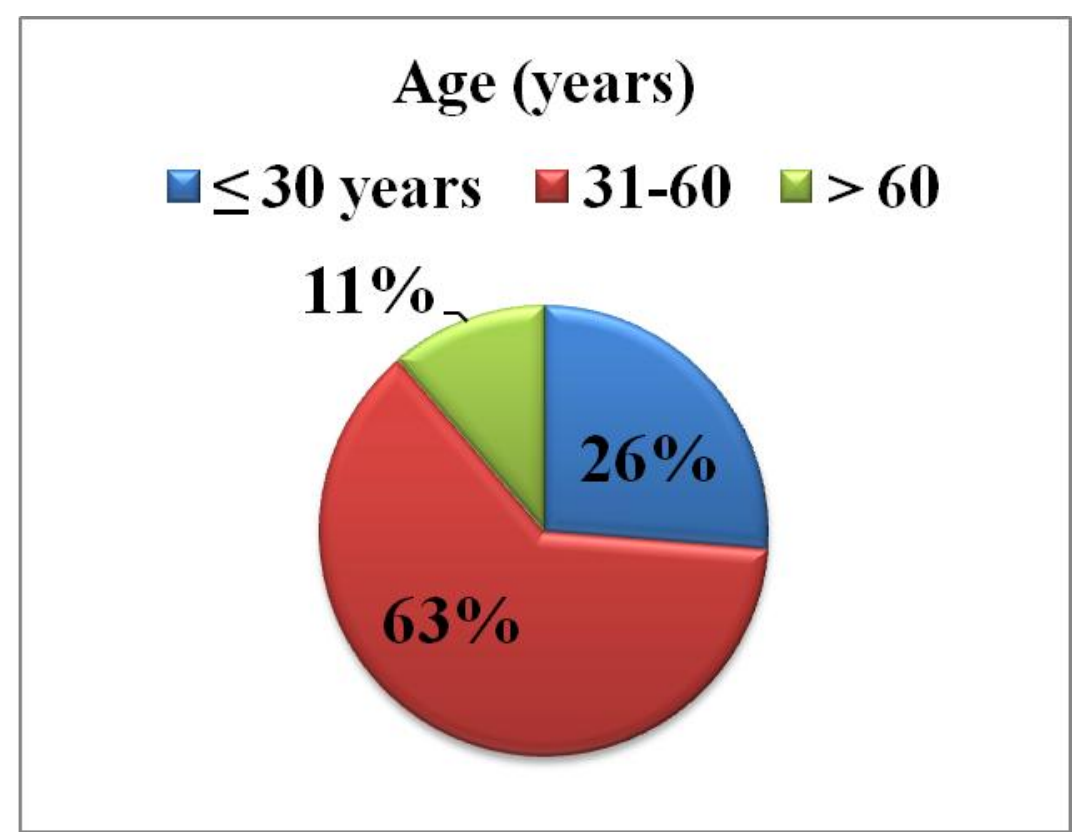


Fig.2 Sex of goat farmers $(n=240)$ in overall Punjab

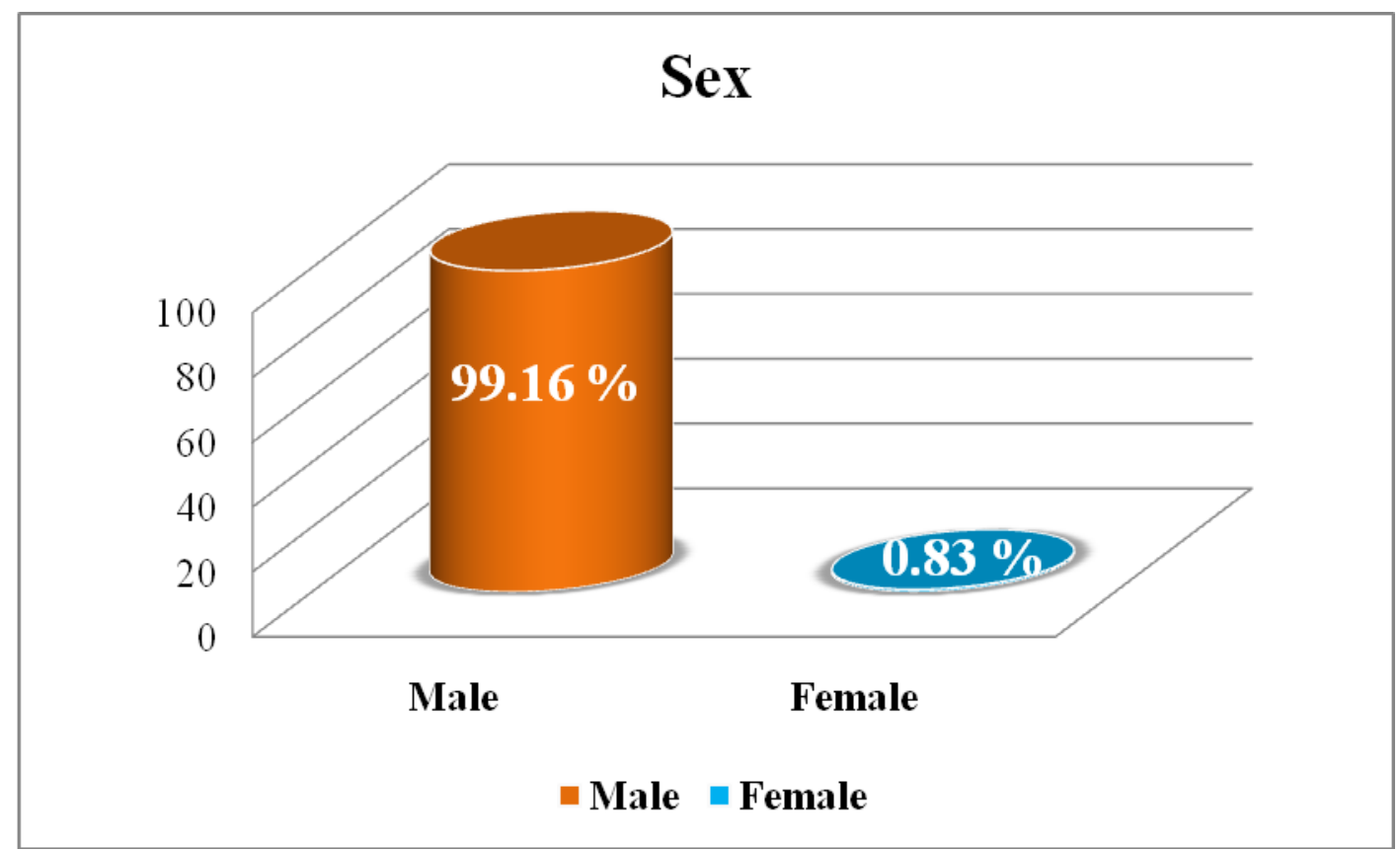

Fig.3 Education level of goat farmers $(n=240)$ in overall Punjab

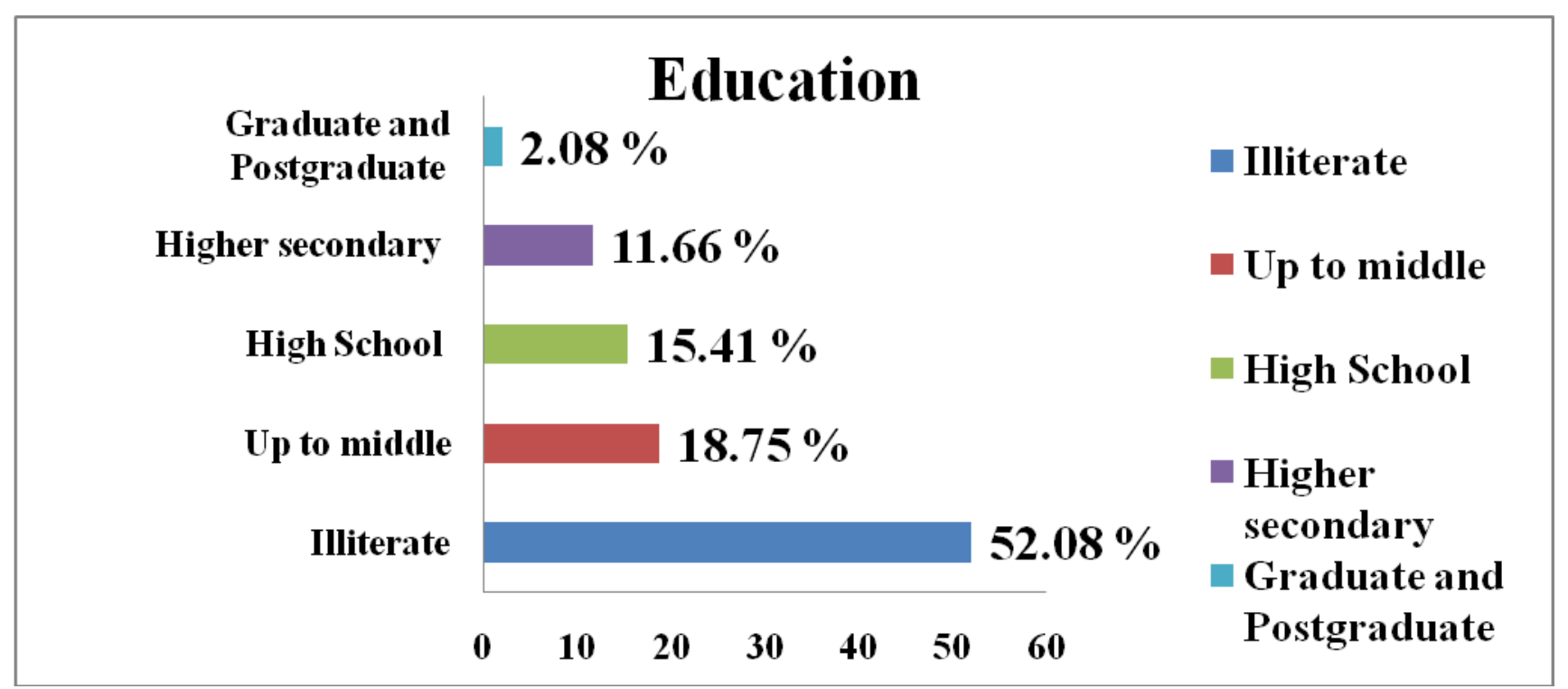


Fig.4 Main occupation of goat farmers $(n=240)$ in Overall Punjab

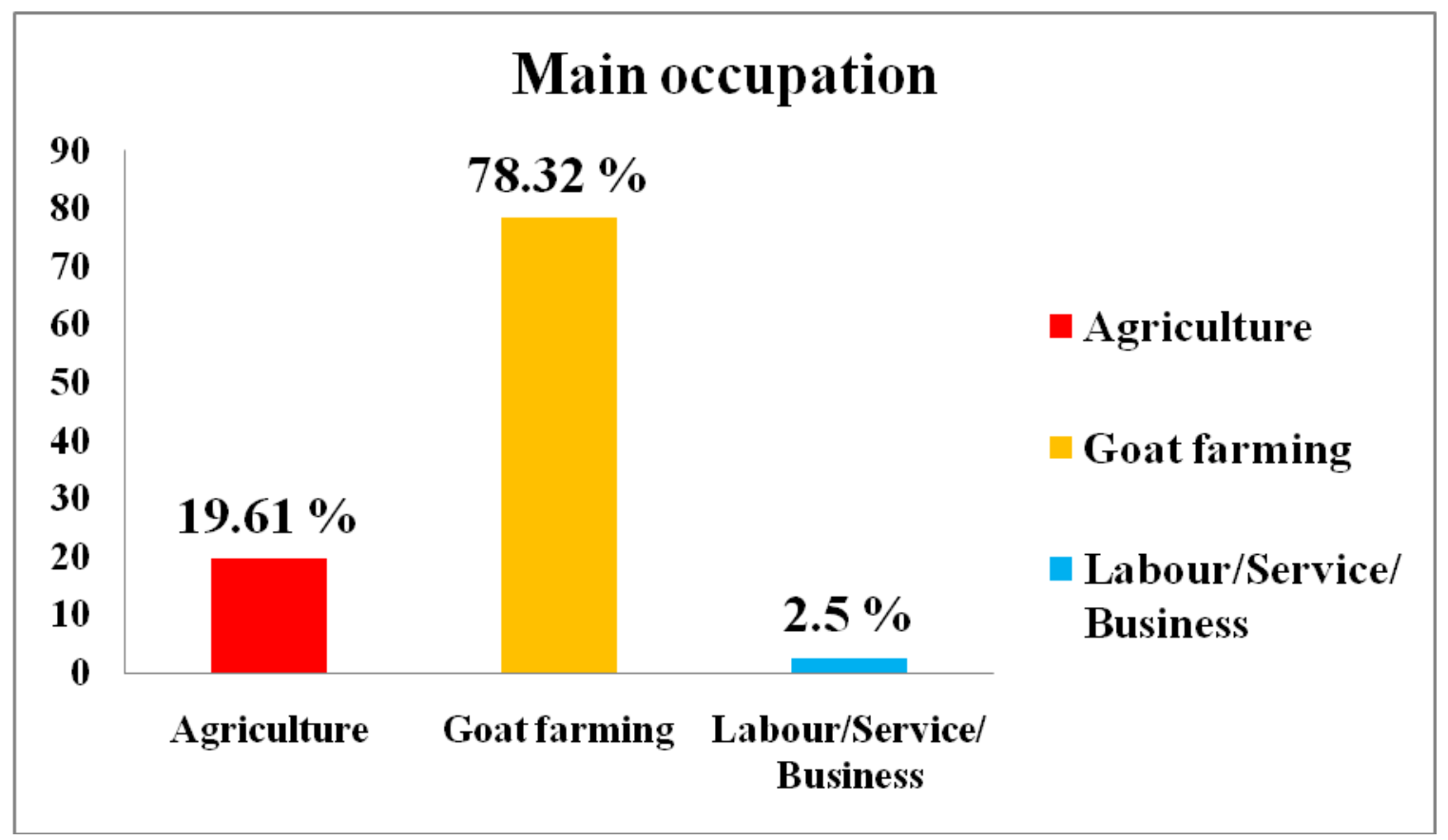

Fig.5 Family size of goat farmers $(n=240)$ in Overall Punjab

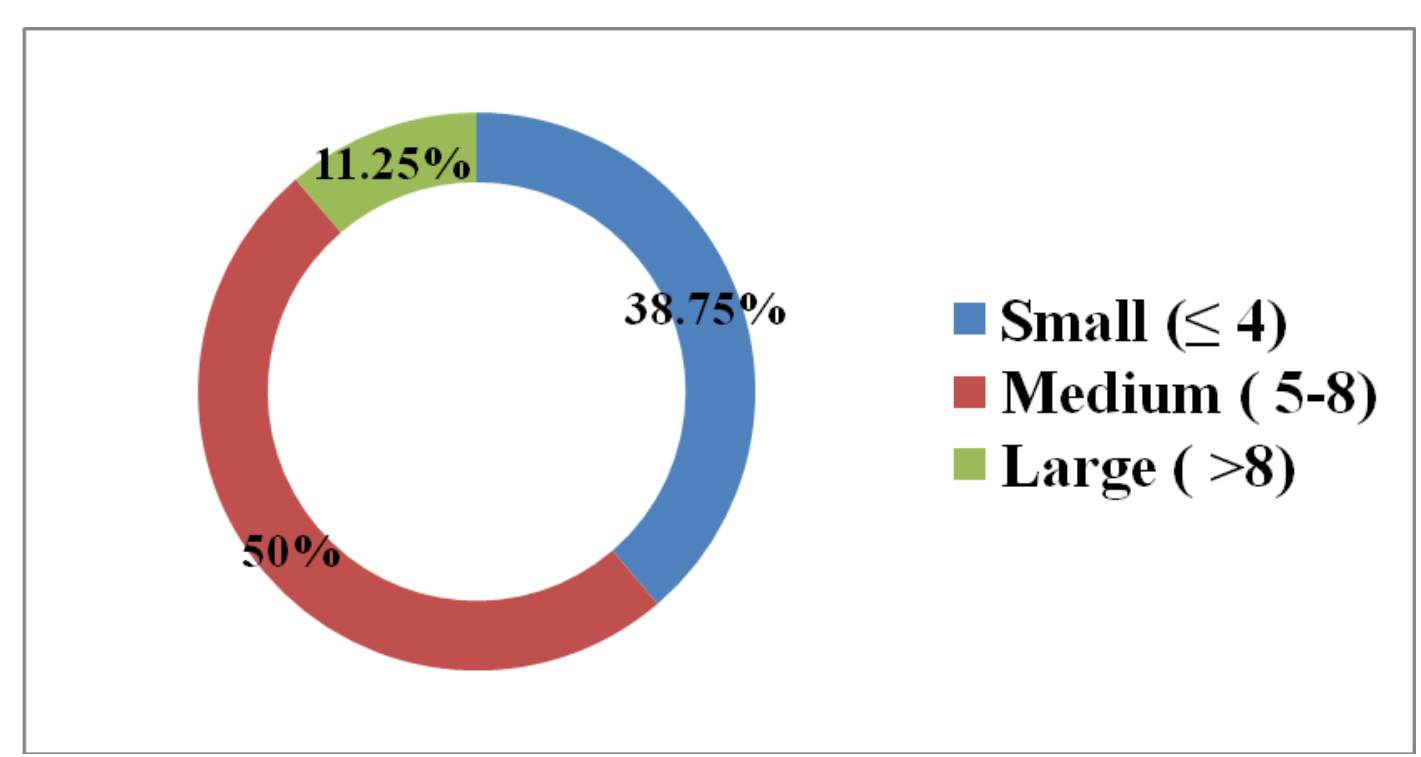


Fig.6 Land holdings (Acres) of goat farmers $(n=240)$ in Overall Punjab

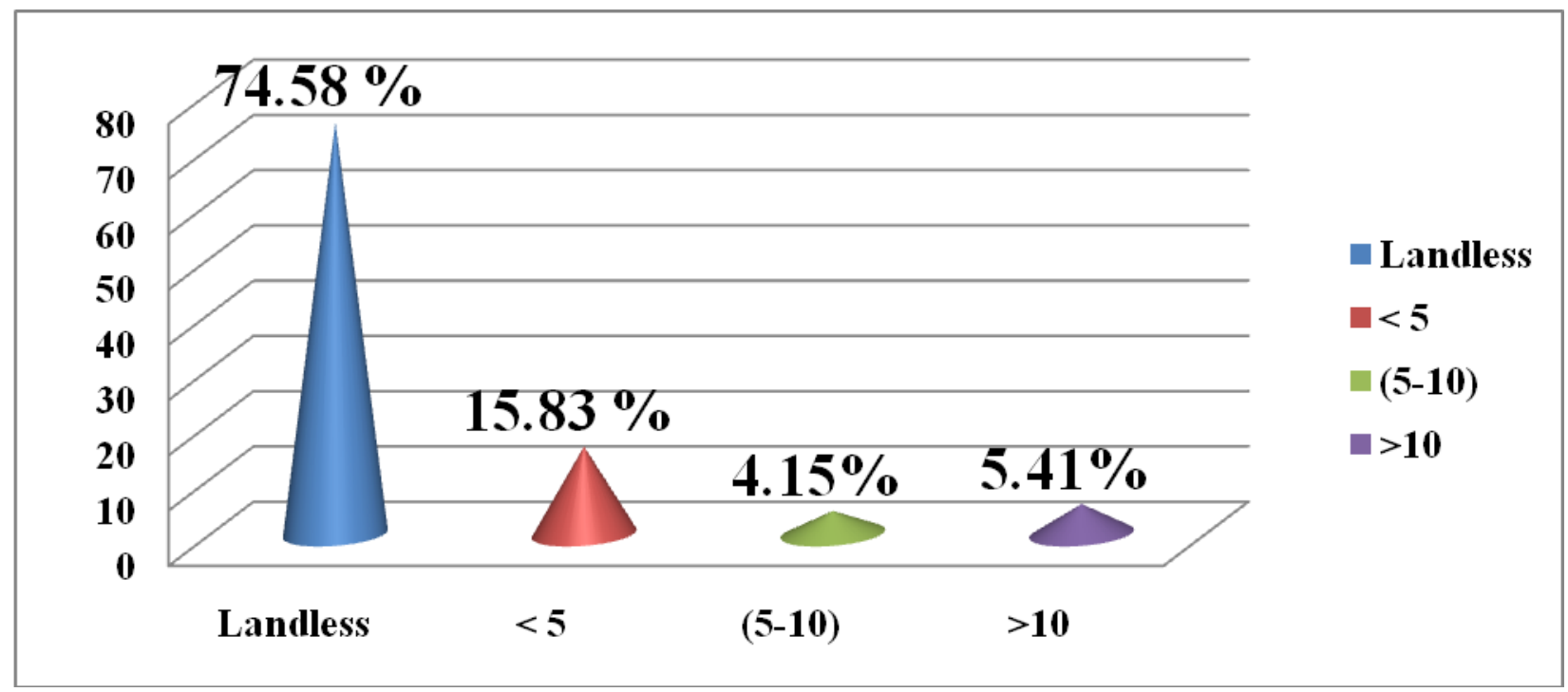

Fig.7 Category of goat farmers $(\mathrm{n}=240)$ in Overall Punjab

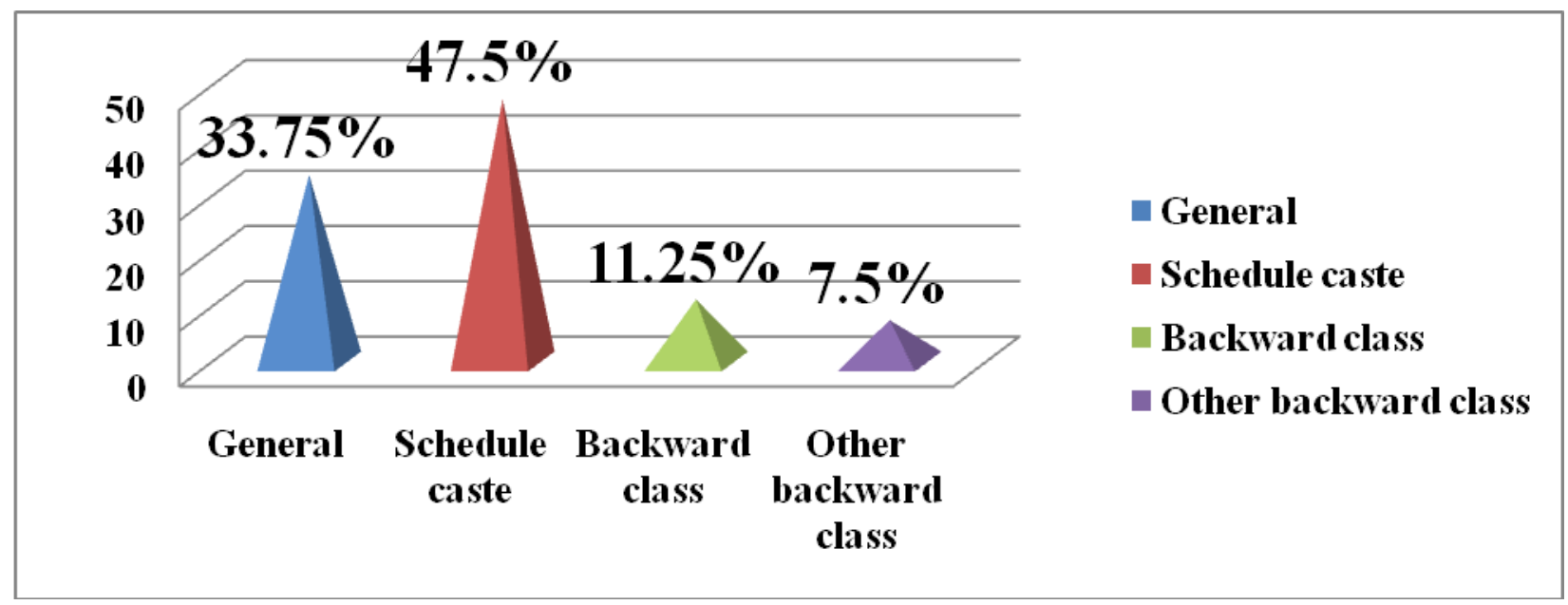

It can be concluded from present study that in Punjab, majority of the goat farmers were between 31-60 years, were male and illiterate. Main occupation of most of the goat farmers was goat farming followed by Agriculture and service/labour. Majority of the goat farmers had medium size families followed by small and large families and most of the goat farmers were landless.

\section{References}

Arya, H. P. S. and Chander, M. 2000. Goat production by landless and small scale farmers in North Indian plains. In Proc. Seventeenth Sympo. Int. Farming Systems Asso. Lake Buena Vista, Florida, USA.

Conference.ifas.ufl.edu/ifsa/ papers/a/a10.doc. 
Chander, M., and Rathod, P. K. 2015. Livestock Innovation System: Reinventing public research and extension system in India. Indian Journal of Animal Science 85 (11):1155-1163.

Kasrija, R. 2016. Effectiveness of instructional material designed on the basis of felt needs of the dairy farmers of Punjab regarding common reproductive conditions. Phd. dissertation, Guru Angad Dev Veterinary and Animal Sciences University, Ludhiana.

Lalwar, V. S., Deoka, D. K., Nimase, K. G., Hale, R. R. and Mandakmale, S. D. 2009. Status of village goat management practices under home tract of Sangamneri goat. The Asian Journal of Animal Science 3(2): 13437.

Lebbie, S. H. B. 2004. Goats under household conditions. Small Ruminant Research. 51(2):131-136.

Mahi, G. S. and Kingra, P. K. 2013. Fundamentals of Agrometerology. Kalyani Publishers, Ludhiana pp 23640.

Meena, M. S. and Malik, B. S. 2009. Participatory identification of reproductive problems among dairy animals and constraints faced by farmers in Haryana. The Indian Journal of Animal Sciences., 79 (11) : 1172-75.

Mohan, B., Sagar, R. L. and Singh, K. 2009. Factors related to promotion of scientific goat farming. Indian Research Journal of Extension Education 13 (2): 67-71.

Neupane, N., Neupane, H. and Dhital, B. 2018. A socioeconomic view of status and prospects of goat farming in rural areas of Nepal Journal of Institute of Agriculture and Animal Science 35: 18.

Peacock, C. P. 1996. Improving Goat Production in the Tropics. A manual for development workers. FARMAfrica/Oxfam, Oxford \{Original not seen: cited by Aziz M A. 2010. Present status of the world goat populations and their productivity Lohmann information 45 (2): 42-52\}

Sharma, M. C., Pathodiya, O. P., Jingar, S. C. and Gaur, M. 2007. A study on socioeconomic status of goat rearers and adoption of management practices. Indian Journal of Small Ruminants 13(1): 75-83.

Singh, M. K., Dixit, A. K., Roy, A. K. and Singha, S. K. 2013. Goat Rearing: A pathway for sustainable livelihood security in Bundelkhand region. Agricultural Economics Research Review 26: 79-88.

Tanwar, P. S., Vaishanava, C. S. and Sharma, V. 2008. A study on socio-economic aspects of goat keepers and management practices prevailed in the tribal area of Udaipur district of Rajasthan. Indian Journal of Animal Research. 42 (1): 71-74.

\section{How to cite this article:}

Sukhwinder Singh, Rajesh Kasrija, Parminder Singh, Jaswinder Singh and Mandeep Singla. 2020. An Appraisal of Demographic Parameters of Goat Farmers of Punjab. Int.J.Curr.Microbiol.App.Sci. 9(01): 136-144. doi: https://doi.org/10.20546/ijcmas.2020.901.015 